\title{
A TENDÊNCIA AGRESSIVA E O SETTING NO ESPAÇO EDUCACIONAL
}

Joyce Garbosa de Azevedo; Fabio Camargo Bandeira Villela

Universidade Estadual Paulista - UNESP, Departamento de Educação, Presidente Prudente; SP. E-mail: joyce98ga@hotmail.com

\section{RESUMO}

No ambiente familiar, na relação entre adultos e crianças e, especialmente, no âmbito escolar, comumente nos deparamos com crianças que manifestam algum comportamento agressivo, seja morder, bater, empurrar ou, em outras circunstâncias, crianças e adolescentes que, costumeiramente, roubam objetos ou agridem pessoas com quem se relacionam. Diante disso, torna-se necessário analisar e compreender as raízes desse problema que vem afligindo cada vez mais adultos, especialmente os professores, que encaram realidades complexas e desconhecidas. Por esse motivo, compreender a agressividade e saber lidar com ela torna-se um instrumento que pode auxiliar o professor diante dessas manifestações.

Palavras-chave: Winnicott, agressividade, desenvolvimento emocional, lúdico, enquadre.

\section{THE AGGRESSIVE TENDENCY AND SETTING IN THE EDUCATIONAL SPACE}

\begin{abstract}
In the family environment, in the relationship between adults and children, and especially in the school field, we often come across children who show some aggressive behavior, whether it is biting, hitting, pushing or, in other circumstances, children and teenagers who usually steal objects or attack people they relate to. Therefore, it is necessary to analyze and understand the roots of this problem that has increasingly afflicting adults, especially teachers, who face complex and unknown realities. For this reason, understanding aggression and knowing how to deal with them becomes an instrument that can help the teacher before these manifestations.
\end{abstract}

Keywords: Winnicott, aggression, emotional development, playful, setting. 


\section{INTRODUÇÃO}

No espaço escolar, é comum nos depararmos com alguma situação que envolve certo nível de agressividade por parte dos alunos, bem como conversas entre os professores sobre agressividade e possíveis soluções para ela. Dentre suas manifestações usuais, podemos destacar contação de mentiras, pequenos furtos, diálogos agressivos e relações hostis.

Para compreender essas manifestações, buscamos aprofundar as raízes da agressividade, bem como suas implicações no desenvolvimento emocional, apresentando suas múltiplas formas. O entendimento da agressividade permite pensar em contribuições para o desenvolvimento da criança quando a energia a ela associada é adequadamente direcionada.

Entretanto, a forma como essa energia se manifesta está estritamente relacionada ao manejo ambiental que foi oferecido ao indivíduo no decorrer de sua infância, podendo tornar-se uma fonte de energia que impulsiona outros aspectos da vida humana ou, devido às complicações nesse processo, tornar-se a exteriorização desse impulso no ambiente, de forma hostil. Nesse último caso, cabe-nos pensar em alternativas que auxiliem o indivíduo a lidar com essa força, sendo a construção de um ambiente específico essencial para que o sujeito elabore os aspectos que o conduzem à expressão agressiva direcionada às pessoas e ao ambiente.

Em suma, o principal objetivo deste trabalho é pesquisar as raízes da agressividade em Winnicott, bem como compreender esse problema que aflige, principalmente, os professores que estão em contato direto com alunos que apresentam comportamentos agressivos e pensar um ambiente que auxilie no manejo dessas tensões e manifestações infantis, assim como favoreça a aprendizagem e a descoberta.

\section{METODOLOGIA}

A presente pesquisa resultou de questões e necessidades que surgiram no decorrer de atendimentos realizados em uma brinquedoteca escolar que se destina a atender alunos indicados pela escola, devido a dificuldades que apresentam na aprendizagem ou no comportamento. $O$ projeto intitulado Desenvolvimento de atividades lúdicas para alunos com dificuldades emocionais, registrado no número CAAE: 52726216.0.0000.5402 do Protocolo do Comitê de Ética, atende alunos de uma escola pública municipal em Presidente Prudente. Os desafios apresentados ensejaram um aprofundamento do tema da agressividade, usando a pesquisa bibliográfica com o propósito de compreendermos as raízes da agressividade, os principais sintomas dessa manifestação e, sobretudo, as formas de manejar esses conflitos e tensões recorrentes, no espaço da sala de aula.

\section{RESULTADOS}

Segundo Winnicott (2015), todos os seres humanos, em sua intrínseca natureza, revelam algum nível de agressividade:

[...] existem certas características na natureza humana que podem encontrar-se em todas as crianças e em todas as pessoas de qualquer idade; [...]. Uma criança pode tender para a agressividade e outra dificilmente revelará qualquer sintoma de agressividade, desde o princípio; [...]. Trata-se, simplesmente, de que as duas crianças estão manobrando de maneiras distintas suas respectivas cargas de impulsos agressivos. (WINNICOTT, 2015, p. 263) 
A agressividade é uma energia que está presente desde o início da vida do sujeito. Entretanto, ela se manifesta de maneiras distintas, de acordo com as necessidades próprias de cada período do desenvolvimento, bem como em função da realidade ambiental em que o sujeito está inserido, especialmente no âmbito relacional, que se manifesta sob as formas de cuidado e provisão das necessidades da criança, ao longo de seu desenvolvimento.

Winnicott (2013) defende que faz parte da tendência inata o próprio desenvolvimento da criatividade do bebê:

O impulso criativo inato desaparece a menos que seja correspondido pela realidade externa ("realizado"). Toda criança tem que recriar o mundo, mas isso só é possível se, pouco a pouco, o mundo for sendo apresentado nos momentos de atividade criativa da criança. A criança procura algo e encontra o seio, e criou-se o seio. O sucesso dessa operação depende da sensibilidade da adaptação da mãe às necessidades da criança, sobretudo no começo. (WINNICOTT, 2013, p. 16)

Dessa forma, a integração do self e o gradual reconhecimento da realidade externa por meio das experiências de criação do seio, advinda da crença de onipotência que o bebê possui, constituem tendências que, apoiadas pela estabilidade e provisão ambiental, tendem a desenvolver-se. Entretanto, há outra força que também impulsiona, até certa medida, o desenvolvimento humano: a agressividade. Segundo Winnicott (1990, p. 137), "Fatores internos podem contribuir para promover a integração; como por exemplo [...] a expressão agressiva, [...] sendo precedida por uma convergência aglutinado do self'".

Para Winnicott (2015), a agressividade manifesta-se ainda nos primeiros momentos de vida, por atitudes que chamamos de socos, mordidas e pontapés. Todavia, pelo fato de ainda não existir uma personalidade integrada e, muito menos, o reconhecimento de uma realidade externa que foge da noção do bebê de ser onipotente, ele não é capaz de "ter uma razão nítida para justificar essas ações" (2015, p. 264).

Os movimentos corporais auxiliam no processo de reconhecimento da realidade externa, onde existem outros objetos distintos do EU do bebê que, até então, não haviam sido reconhecidos como tais. Além disso, os movimentos corporais constituem uma atividade prazerosa para o bebê, no sentido de permitir encontrar um objeto (WINNICOTT, 2015, p. 264). Em certo sentido, o movimento, o encontro de um objeto externo e a obtenção de prazer estão relacionados à atividade criativa, que citamos anteriormente, de ilusão do seio que satisfaz um impulso e uma necessidade física. Portanto, tal movimento mantém relações e, de certa forma, fornece uma continuidade na experiência criativa, enriquecendo as experiências que integram um self saudável e, sobretudo, lançando as bases para um relacionamento entre a realidade interna e pessoal e a realidade externa e compartilhada.

Podemos compreender que essas primeiras pancadas infantis levam a uma descoberta do mundo que não é o eu da criança e ao começo de uma relação com objetos externos. 0 que muito em breve será um comportamento agressivo não passa, portanto, no início, de um simples impulso que desencadeia um movimento e aos primeiros passos de uma exploração. A agressão está sempre ligada, desta maneira, ao estabelecimento de uma distinção clara entre o que é e o que não é o eu. (WINNICOTT, 2015, p. 264).

Diante da ambivalência das forças agressivas que atuam no interior do sujeito e do caos próprio dessa realidade, é necessário que haja certo manejo externo, especialmente no sentido de oferecer um suporte para que o desenvolvimento e as forças que o conduzem sejam direcionadas em favor do crescimento do indivíduo. Segundo Winnicott (2005, p. 98) "a riqueza da personalidade é, predominantemente, um produto do mundo de relações internas que a criança está construindo [...] através do dar e receber psíquico [...] paralelo ao dar e receber físico". 
À medida que o sujeito se desenvolve, o impulso agressivo passa a ser reconhecido como tal. Isso decorre do processo de integração do self e do reconhecimento da mãe como alguém distinto e não mais como uma extensão de si próprio.

Esse desenvolvimento implica um ego que começa a ser independe do ego auxiliar da mãe, e pode-se agora dizer que existe um lado de dentro do bebê e, por conseguinte, um lado de fora. [...]. Esta riqueza pessoal [o self - JGA] desenvolve-se a partir da experiência simultânea amor-ódio, a qual implica a realização de ambivalência, cujo enriquecimento e aprimoramento leva à emergência do envolvimento. (WINNICOTT, 2005, p. 114).

Com o desenvolvimento da capacidade de envolvimento o sujeito passa a relacionar-se e sente a necessidade de fornecer elementos construtivos ao ambiente externo, constituindo uma nova etapa que tem início nesse período, mas que tende a amadurecer e a aperfeiçoar-se durante toda a vida, seja por meio da brincadeira durante a infância, seja no trabalho da vida adulta (WINNICOTT, 2005, p. 116). Assim, a capacidade de envolvimento é resultado do sentimento de culpa gerado pelo impulso agressivo. Em razão disso, o sujeito elabora meios de oferecer elementos construtivos em reparação ao ataque resultante do impulso.

É pelo fato de os impulsos agressivos primários manterem forte relação com a criatividade e, portanto, com a atividade lúdica, que observamos atitudes e comportamentos agressivos durante a brincadeira. Além disso, o desenvolvimento humano é desafiador e, embora haja uma determinada inclinação ao amadurecimento, o crescimento emocional envolve forças do mundo interno e seus impetuosos desejos, mas que, ao mesmo tempo, precisam adequar-se às circunstâncias do mundo externo (WINNICOTT, 2015, p. 161-163).

Quando há o fornecimento de um ambiente satisfatório, o indivíduo pode direcionar essa energia para atividades saudáveis, que auxiliem no processo de amadurecimento. Todavia, além de o brincar imaginativo ser um importante canal para isso, ele também auxilia na elaboração de conflitos de fases anteriores em que o sujeito não pôde elaborar de forma satisfatória, ou mesmo na elaboração de conflitos atuais.

Até aqui, tratamos de um desenvolvimento que ocorreu de forma ao menos satisfatória para que a criança pudesse alcançar a capacidade de brincar e, por meio disso, pudesse canalizar seus impulsos agressivos. Entretanto, é normal que ocorram falhas, recaídas ou regressões no decorrer desse processo e o sujeito não consiga direcionar essa energia a uma atividade construtiva e manifestar de forma lúcida comportamentos agressivos.

A tendência antissocial, como define Winnicott (2005, p. 270), é caracterizada por um estágio que precede a delinquência e que pode ser remediada. Dentre alguns sintomas, podemos citar "o furto [...] associado à mentira" (WINNICOTT, 2005, p. 141) e "a avidez estreitamente relacionada à inibição de apetite" (WINNICOTT, 2005, p. 143).

Existem [...] duas direções na tendência anti-social .... Uma [...] é representada tipicamente pelo roubo e a outra pela destrutividade. Numa direção, a criança procura alguma coisa, [...], não a encontrando, busca-a em outro lugar, quando tem esperança. Na outra, a criança está procurando aquele montante de estabilidade ambiental, que suporte a tensão resultante do comportamento impulsivo. É a busca de um suprimento ambiental que se perdeu, uma atitude humana [...]. (WINNICOTT, 2005, p. 140-141).

A tendência antissocial, portanto, embora exija certo manejo ambiental, significa que ainda há, da parte da criança ou do jovem, a busca de amor, cuidado ou contenção, de certa maneira, a tendência antissocial enseja esperanças de sua reversão, pelo fato de representar, de forma deformada e não reconhecida, um pedido de ajuda aos cuidadores, à escola ou à sociedade (WINNICOTT, 2005, p. 139).

Dessa forma, considerando a compreensão de Winnicott sobre a agressividade, discutida ao longo desse trabalho e, visando à concepção e à construção de um ambiente físico e relacional que seja adequado às expressões que envolvem as necessidades humanas e considerando que o ambiente seja uma sala de aula, há múltiplos determinantes que influenciam no processo 
educacional: a presença de diversos alunos com dificuldades distintas, a própria lotação da sala e as dificuldades que o professor enfrenta. Dessa forma, torna-se essencial pensar em um espaço que não responda às expressões agressivas somente no momento em que elas ocorrem, mas que, sobretudo, haja a construção de uma atmosfera que contenha e, em certo sentido, adeque esses impulsos antes mesmo de eles acontecerem ou, quando isso não for possível, que haja um ambiente pronto para conter e lidar com eles.

Pensando na construção desse ambiente, Villela e Archangelo (2014) apresentam a ideia de enquadre dentro da proposta de construção de uma escola significativa. O conceito de enquadre é definido como o "estabelecimento processual de condições ótimas para o desenvolvimento de atividades que centralmente envolvam relações humanas" (VILLELA; ARCHANGELO, 2014, p. 116), ou seja, tendo em vista as relações que se estabelecem dentro da sala de aula, a constituição progressiva do enquadre torna-se fundamental na tentativa de criar e desafiar o aluno a ser e a aprender. A construção do enquadre visa apresentar ao aluno o que há de melhor no espaço escolar: as experiências, a aprendizagem e as relações que se estabelecem. Dessa forma, ao chegar na escola, o aluno se sentirá acolhido pelo ambiente.

Entretanto, visando ao estabelecimento do enquadre, algumas posições habituais por parte dos professores e da escola em geral devem ser evitadas, por exemplo, a construção de regras disciplinares previamente estabelecidas no início das aulas, pois, de forma subjetiva, o aluno é visto como uma ameaça à ordem e à disciplina do local e, por isso, passa a responder ao ambiente de forma hostil e desafiadora. (VILLELA; ARCHANGELO, 2014, p. 124). Os autores também afirmam no mesmo livro que,

\begin{abstract}
Isso não significa que não deva haver uma ou outra norma no espaço escolar, mas que as condutas e as formas de ser dos alunos na sala de aula não devem ser reguladas exclusiva e fundamentalmente pelas normas. [...], os alunos devem encontrar mais do que normas na relação com a escola e com os professores; devem encontrar uma promessa de experiências enriquecedoras, um espaço para a espontaneidade e para o amadurecimento. (VILLELA; ANCHANGELO, 2014, p. 126-127).
\end{abstract}

Ao criar esse ambiente, automaticamente, os sujeitos que usualmente manifestam condutas antissociais, tendem a se sentir-se acolhidos pelo ambiente que favorece estabilidade e, quando necessário, exige certo limite, mas, ao mesmo tempo, lhes propõe liberdade para criar e imaginar, abrindo caminho para a elaboração, usando da brincadeira ou da relação transferencial, isso é, a capacidade de transpor sentimentos relacionados a vínculos passados em direção a uma outra pessoa - em geral, a professora - capaz de conter e oferecer apoio para que ocorra a elaboração interna. Esse espaço tende a auxiliar o professor na tarefa educativa e no próprio relacionamento e manejo dos conflitos em sala, possibilitando a expressão, elaboração de conflitos e, sobretudo, o desenvolvimento da capacidade de imaginação e cognição infantil.

\title{
DISCUSSÃO
}

Podemos afirmar que as primeiras manifestações agressivas podem ser percebidas ainda em um bebê recém-nascido que não reconhece a realidade externa como distinta de si, mas como uma extensão do seu próprio corpo, de suas necessidades e fantasias e, através de movimentos corporais impulsionados pela agressividade e, com o apoio de um ambiente suficientemente bom, há a descoberta do ambiente externo e compartilhado.

Gradativamente, à medida que ocorre a integração da personalidade e o reconhecimento da realidade externa, não mais como uma extensão de si, mas como algo distinto, o bebê ou a criança pequena começa a sentir culpa pelas agressões à mãe, vista como boa e passa a oferecer elementos construtivos para ela ou para quem a substitua nessa relação. A destruição e a agressividade, portanto, são canalizadas para atividades como a brincadeira e, posteriormente, com o desenvolvimento dessas, ao trabalho, às artes e à cultura na idade adulta, que ocupam o 
mesmo espaço do brincar na infância. Nem todo impulso, entretanto, pode ser sublimado, conforme nos lembra Freud (1988, p. 64), mas, pode, ao menos alternativamente, chegar a uma expressão mais adequada.

Entretanto, é normal que ocorram falhas na elaboração dessa energia agressiva no decorrer do desenvolvimento e, por isso, alguns sujeitos manifestam comportamentos agressivos de modo exacerbado no espaço escolar. Em geral, os indivíduos que possuem essa tendência, ou seja, que apresentam um comportamento antissocial, necessitam de um auxílio do ambiente que esteja pronto para acolher, mas, sobretudo, para conter e manejar essa energia de forma adequada, auxiliando-o a elaborar seus conflitos por meio de um espaço que tenha significado e no qual ele possa se apoiar.

\section{CONCLUSÃO}

A agressividade é parte da vida e da natureza humana; entretanto, para que se converta em algo saudável e proveitoso, é necessário um ambiente suficientemente adaptado que direcione esses impulsos a experiências de construção que se manifestam durante a infância, através da brincadeira e, posteriormente, na vida adulta, no trabalho, na admiração das artes, na participação da cultura. Em suma, o impulso agressivo é canalizado e constitui uma energia para o desenvolvimento saudável e que valorize a criatividade e expansão do self.

No caso de crianças com comportamentos antissociais, inexiste, do ponto de vista da criança, um bom ambiente por um tempo necessário para que esse processo inicial de envolvimento com o ambiente ocorra de forma saudável. O sujeito pode desenvolver essa tendência antissocial com a perda de cuidados e proteção dos pais ou cuidadores, o que comumente percebemos no espaço escolar sob diversas formas.

Nesse sentido, torna-se necessária a construção de um espaço que maneje essas expressões por meio das relações que se estabelecem, auxiliando no processo de elaboração dessas lacunas no desenvolvimento. Assim, a escola fornece, no próprio momento do processo educativo regular, sua contribuição à criança, em complementação à família e, em alguns casos, em substituição aos cuidados emocionais básicos que não puderam ser oferecidos à criança por sua própria família.

Para isso, propomos a adoção da perspectiva do enquadre em sala de aula em substituição a um sistema rígido de normas disciplinares, perspectiva apresentada no livro Fundamentos da escola significativa (VILLELA; ARCHANGELO, 2014, 111-136), não apenas nas circunstâncias discutidas, mas como um modo de organização que potencializa as relações e experiências humanas, especialmente no espaço escolar. Por meio disso, são oferecidas aos alunos vivências significativas e a construção de um vínculo que favoreça o desenvolvimento geral do sujeito.

\section{REFERÊNCIAS}

FREUD, S. Obras psicológicas completas de Sigmund Freud: edição standard brasileira. Direção geral de tradução de Jayme Salomão. 3. ed. Rio de Janeiro: Imago, 1988. v. 11, p. 17-65.

VILLELA, F.; ARCHANGELO, A. Fundamentos da escola significativa. 4. ed. São Paulo: Loyola, 2014. v. 1.

WINNICOTT, D. W. Natureza humana. Rio de Janeiro: Imago, 1990.

WINNICOTT, D. W. Privação e delinquência. 4. ed. São Paulo: Martins Fontes, 2005.

WINNICOTT, D. W. A família e oz desenvolvimento individual. 4. ed. São Paulo: Martins Fontes, 2013. 
WINNICOTT, D. W. A criança e o seu mundo. 6. ed. Rio de Janeiro: LTC, 2015. 